\title{
ASPEK LEKSIKAL DAN GRAMATIKAL PADA LIRIK LAGU “NYANYIAN RINDU” EBIET G ADE
}

\author{
Oktarina Puspita Wardani dan Turahmat \\ Universitas Islam Sultan Agung \\ oktarinapw@unissula.ac.iddan lintangsastra@unissula.ac.id,
}

koresepondensi penulis:oktarinapw2unissula.ac.id telp 08562788351

\begin{abstract}
Abstrak
Alat komunikasi dibutuhkan oleh manusia sebagai alat untuk berinteraksi dengan lingkungan. Salah satu alat komunikasi yang bisa digunakan adalah bahasa. Lagu merupakan sebuah wacana yang memiliki unsur piuitis dalam liriknya. Lagu memiliki karakter masing-masing dairi tiap pengarang. Kekuatan dalam lagu dapat dilihat dari liriknya. Wacana lagu dapat dikategorikan sebagai wacana puisi dilihat dari segi genre sastra tergolong wacana rekreatif. Wacana lagu dapat dikategorikan sebagai wacana puisi dilihat dari segi genre sastra tergolong wacana rekreatif. Permasalahan dalam penelitian ini ialah bagaimana aspek leksikal dan gramatikal pada lirik lagu "Nyanyian Rindu" Ebiet. Ade. Tujuannya ialah mendeskripsikan bagaimana bentuk gramatikan dari litik lagu tersebut. Penelitian ini menggunakan metode deskriftif kualitatif. Teknik pengumpulan data menggunakan teknik catat. Analisis data menggunakan analisis kualitatif. Terdapat 34 data yang menunjukkan aspek gramatikal dalam lirik lagu Nyanyian Rindu" karya "Ebiet G. Ade". pengacuan terdiri atas 21 data, pelesapan 10 data, dan konjungsi 1 data. Aspek leksikal menunjukkan 2 data terdiri atas 1 data kolokasi dan 1 data repetisi.
\end{abstract}

Kata kunci: gramatikal, leksikal, dan Ebiet G. Ade

Abstrack

Communication tools are needed by humans as a tool to interact with the environment. One of the communication tools that can be used is language. The song is a discourse that has a poetic element in the lyrics. The song has the character of each author. Strength in a song can be seen from the lyrics. Song discourse can be categorized as poetry discourse in terms of literary genre classified as creative discourse. Song discourse can be categorized as poetry discourse in terms of literary genre classified as creative discourse. The problem in this study is how the lexical and grammatical aspects of the lyrics to the song "Song of Miss" Ebiet. Ade The aim is to describe how the grammatical form of the song lytic. This study uses a qualitative descriptive method. Data collection techniques using note taking. Data analysis uses qualitative analysis. There are 34 data that show the grammatical aspects of the song Nyanyian Rindu song "by" Ebiet G. Ade ". reference consists of 21 data, absorption of 10 data, and 1 data conjunction. The lexical aspect shows that 2 data consist of 1 data collocation and 1 data repetition.

Keywords: grammatical, lexical, and Ebiet G. Ade 


\section{PENDAHULUAN}

Alat komunikasi dibutuhkan oleh manusia sebagai alat untuk berinteraksi dengan lingkungan. Salah satu alat komunikasi yang bisa digunakan adalah bahasa. Masyarakat bisa komunikasikan pesan kepada masyarakat melalui bahasa. Dilihat dari segi pemakaiannya, alat komunikasi dibedakan atas bahasa verbal dan bahasa nonverbal (Setiawan, 2012:15). Komunikasi verbal meliputi sarana komunikasi secara lisan dan tulisan. Demikian halnya dengan sebuah wacana atau teks.

Wacana merupakan kajian bahasa yang paling tinggi dilihat dari struktur hieararkhisnya. Kalimat sebagai salah satu unsur pembentuk wacana yang memiliki syarat gramatikal dan leksikal. Wacana bisa dibedakan menjadi wacana lisan dan tulis sehingga maknanya mampu dipahami oleh pembaca secara utuh. Slah satu bentuk wacana ialah wacana lagu. Wacana lagu dapat juga dikategorikan sebagai wacana ekspresif.

Lagu merupakan sebuah wacana yang memiliki unsur piuitis dalam liriknya. Lagu memiliki karakter masingmasing dairi tiap pengarang. Kekuatan dalam lagu dapat dilihat dari liriknya. Pengarang mampu bercerita serta menyampaikan pesan kepada pendengar melalui lirik. Lirik lagu salah satu cara untuk menyampaikan ekspresi pengarang. Pengarang mengeskpresikan rasa ke dalam kata-kata yang dirangkai dan bahasa yang dibuat untuk daya tarik dalam lagu itu.
Wacana lagu dapat dikategorikan sebagai wacana puisi dilihat dari segi genre sastra tergolong wacana rekreatif. Puisi adalah karya sastra dengan bahasa yang dipadatkan, dipersingkat, dan diberi irama dengan bunyi yang padu dan pemilihan kata-kata yang kias (imajinatif). Kata yang singkat dan padat dipilih yang memiliki persamaan bunyi (rima), mewakili makna yang lebih luas dan banyak, oleh karena itu dicarikan konotasi dan makna yang tambahan dan dibuat bergaya dengan bahasa figurative (Waluyo, 2002:1).

Permasalahan dalam penelitian ini ialah bagaimana aspek leksikal dan gramatikal pada lirik lagu "Nyanyian Rindu" Ebiet. Ade. Penelitian ini memiliki tujuan untuk mendeskripsikan bagaimana bentuk gramatikan dari litik lagu tersebut. Serta makna leksikal pada lirik lagu "Nyanyian Rindu" Ebiet G. Ade. Ciri dari lagu Ebiet berbeda dengan lagu pengarang lain dari segi gramatikal dan leksikalnya.

Aspek gramatikal wacana meliputi: (a) pengacuan (reference), ialah satuan tertentu yang mengaju pada satuan bahasa lain. (b) Penyulihan (substitution) ialah penggantian satuan bahasa tertentu dengan satuan bahasa lain dalam sebuah wacana agar mendapatkan unsur pembeda. (c) Pelesapan (ellipsis) yaitu pengilangan satuan bahasa tertentu yang telah disebutkan sebelumnya. (d) Perangkaian (conjunction) ialah menghubungkan unsur satu dnegan lainnya dalam satu wacana. (Sumarlam, 2009 : 23). 
Aspek leksikal atau kohesi leksikal adalah hubungan antar unsur dalam wacana secara sistematis (Sumarlam, 2009:35). Kohesi leksikal dalam wacana ada enam macam, yaitu (1) repetisi (pengulangan) ialah pengulangan satuan bahasa yang dianggap penting untuk memberikan tekanan dalam konteks.. (2) Sinonimi (padan kata) adalah ungkapan yang memiliki makna sama dengan ungkapan lain. (3) Kolokasi (sanding kata) adalah pilihan kata yang dugunakan secara berdampingan. (4) Hiponimi (hubungan atas-bawah), adalah makna kata dianggap sebagai bagian dari makna bahasa lain. (5) antonimi (lawan kata), adalah satuan bahasa yang memiliki makna yang berlawanan dengan satuan bahasa lainnya. (6) ekuivalensi (kesepadanan) adalah hubungan kesepadanan bahasa satu dengan lainnya dalam sebuah paradigma.

Ebiet G. Ade merupakan musisi yang akrab dengan alam dan duka derita kelompok tersisih. Lewat lagulagunya yang ber-genre balada, pada awal karirnya, ia 'memotret' suasana kehidupan Indonesia di akhir tahun 1970-an hingga sekarang. Tema lagunya beragam, tidak hanya tentang cinta, tetapi ada juga lagu-lagu bertemakan alam, sosial-politik, bencana, religius, keluarga, dll. Sentuhan musiknya sempat mendorong pembaruan pada dunia musik pop Indonesia.

\section{METODE PENELITIAN}

Penelitian ini menggunakan metode deskriftif kualitatif dengan mendeskripsikan satuan linguistik. Gejala bahasa diklasifikasikan dan dianalisis berasarkan rumusan masalah. Dayta yang digunakan berupa kata, frasa, klausa pada lirik lagu. Sumber data diambil dari lagu Nyanyian Rindu" karya"Ebiet G. Ade"

Teknik pengumpulan data menggunakan teknik catat. Analisis data menggunakan analisis kualitatif dengan runtutan a) reduksi data, b) display data, dan c) analisis data. Keabsahan data dalam penelitian ini menggunakan metode Trianggulasi. Trianggulasi menurut Moleong (2014: 330) adalah teknik pemerikasaan keabsahan data yang sesuatu yang lain diluar data itu untuk pengecekan atau sebagai pembanding terhadap data itu. Metode trianggulasi menurut Denzin (dalam Moleong, 2014:330)

\section{HASIL PENELITIAN DAN PEMBAHASAN}

Analisis aspek gramatikal "Nyanyian Rindu" ini meliputi pengacuan (referensi), pelesapan (ellipsis), dan perangkaian (konjungsi). Terdapat 31 data yang menunjukkan aspek gramatikal dalam lirik lagu Nyanyian Rindu" karya"Ebiet G. Ade". Data meliputi Pengacuan (referensi), dan Perangkaian (konjungsi)

a. Pelesapan (elipsis)

a) Pengacuan (referensi)

Pengacuan (referensi) merupakan satu alat kohesi wacana. Dalam lagu "Nyanyian Rindu" terdapat tiga pengacuan, yaitu pengacuan persona, 
pengacuan demonstrasi, dan pengacuan komparatif.

1. Pengacuan Persona

Pengacuan persona tunggal terikat dengan -ku dan ku-.

1) Apa yang seharusnya aku lakukan (I.2)

2) Ini, aku yang tertidur (III.9)

3) Coba engkau katakan padaku (I.1)

4) Kau ada disampingku (III.2)

Dalam lagu "Nyanyian Rindu" ditemukan dua pronomina persona, yaitu, (1) pronomina persona pertama tunggal, terdiri atas (a) pronominal persona pertama tunggal aku, (b) pronominal persona pertama tunggal bentuk terikat lekat kanan -ku, pada kutipan:Pengacuan persona pertama berfungsi sebagai subjek pelaku dalam lirik tersebut. Pengacuan yang menandai "aku, ku" memiliki fungsi subjek pelaku. Pengacuan persona -ku mekelat pada kanan kata termasuk da;am pengacuan endoforis. Pemakaian sejajr dengan kalimat aktif.

5) Coba engkau katakan padaku (I.1)

6) Tak mampu mengusir kau yang (II.6)

7) Kau ada disampingku (III.2)

8) Coba engkau dengar lagu (III.8)

9) Meski hanya sekilas kau (IV.2)

10)Wajahmu terbayang (I.4)

11)Wajahmu yang bening sejuk (III.13)

12)Bersama, tatapmu membasuih luka. (IV.5)

Pronomina persona kedua tunggal terdiri atas (a) pronomina persona kedua tunggal bentuk bebas kau, dan b) pronominal bentuk kedua tunggal bentuk terikat lekat kanan -mu . berikut ini penggunaan pronomina perdona kedua tungga dalam lirik lagu yang terdapat dalam kutipan. Pengacuan persona kedua "kau, mu" merupakan pengacuan endoforis karena acuan yang digunakan terdapat dalam teks.

13)Kapan lagi kita akan bertemu (IV.1) 14)Kapan lagi kita nyanyi (IV.4)

Bentuk pronomina yang ketiga adalah kita sebagai pronominal persona pertama jamak bentuk bebas. Pronominal persona pertama tunggal aku, -ku merupakan pengacuan eksoforis, karena yang diacu berada di luar teks, yaitu penulis lagu Ebiet G. Ade. Pronominal persona kedua tunggal kau dan mu- juga merupakan pengacuan eksoforis yang mengacu pada pacar Ebiet G. Ade, Kita sebagai pronominal persona pertama jamak merupakan pengacuan endoforis karena mengacu pada aku dan kau.Pengacuan Demonstrasi

Pengacuan ini meliputi pengacuan demonastrasi waktu dan tempat.

1) Pengacuan pronominal demonstrasi waktu, yaitu pengacuan pronominal waktu larut dan malam, dapat dilihat dari kutipan berikut.

15)Lakukan bila larut tiba, (I.3)

16)Bila malam (III.4)

2) Pengacuan pronominal demostrasi tempat, yaitu menunjukkan pantai, kuta, bukit, kintamani, danau biru, yang tampak dalam kutipan berikut:

17)Gemuruh ombak di pantai (II.1) 
18)Kuta (II.2)

19)Sejuk lembut angina di bukit (II.3)

20)Kintamani, gadis-gadis kecil (II.4)

21)Sama-sama arungi danau biru (III.3)

Penggunaan pengacuan demonstrasi terdapat penanda waktu dan tempat. Pengacuan yang paling sering digunakakan ialah pengacuan

demontrasi tempat. Bentuk pengacuan tempat pada lirik lagu "Nyanyian Rindu" ialah "pantai, kuta, bukit, kintamani, danau biru". Pengacuan demontrasi waktu dalam lirik lagu tersebut terdapat dalam kata "larut dan malam".

\section{b. Pelesapan (elipsis)}

Pelesapan merupakan penghilangan kata atau sebagian kata dari sebuah kalimat. Pelepasan dekat dengan substitusi (secara gramatikal). Hal itu disebabkan pelesapan dapat disuratkan sebagai substitusi kosong. Terdapat kepaduan wacana dalam pelepasan agar tercapainya keefektifan kalimat. Pelesapan terdiri atas pelesapan (elipsis) awalan (prefiks), pelesapan untuk pemadatan kata Dn pelesapan bentuk peran pelaku .

Dalam wacana lagu "Nyanyian Rindu" ditemukan pelesapan (elipsis) awalan (prefiks). Hal tersebut dapat dilihat pada kutipan berikut.

22) a. Kapan lagi kita nyanyi (IV.4)

b. Kapan lagi kita menyanyi

23) a. Kerinduan ini semakin dalam (I.5) b. Kerinduan ini semakin mendalam 24)a. Kau ada disampingku (III.2)

b. Kau berada disampingku

25) a. Sama-sama arungi danau biru (III.3)

b. Sama-sama mengarungi danau biru

26) a. Coba engkau dengar lagu (III.8)

b. Coba engkau mendengar lagu

27)a. Coba engkau katakan padaku (I.1)

b. Coba engkau mengatakan padaku

Pada kutipan 22a) terjadi pelesapan bentuk prefiks (me-), pada kata menyanyi, pada kutipan 23a) dan 26)a terjadi pelesapan bentuk men- pada kata mendalam dan mendengar, pada kutipan 24)a terjadi pelesapan bentuk ber- pada kat berada, pada kutipan dan 25)a, 27)a terjadi pelesapan bentuk meng- pada kata mengarungi dan mengatakan.

28) a. Lakukan bila larut tiba, (I.3)

b. Lakukan bila larut tiba

29) a. Tak mampu mengusir kau yang

(II.6)

b. Tak mampu mengusir kau yang

Pelesapan untuk pemadatan kata terjadi juga dengan penghilangan “-id-“ pada tidak dan "apa" pada apabila.. Selain bentuk diatas masih ditemukan pelesapan bentuk peran pelaku kita dan -ku. Hal itu dapat dilihat pada kutipan berikut.

30) a. Sama-sama arungi danau biru (III.3)

b. Sama-sama kita arungi danau biru

31) a. Mata enggan terpejam (III.5)

b. Mataku enggan terpejam 
c. Perangkaian (konjungsi)

Terdapat dua bentuk perangkaian (konjungsi), yaitu konjungsi dan yang menggambarkan

$$
\text { perangkaia }
$$

n penggabungan. Konjungsi memeiliki peranan penting dalam kepaduan kalimat. Konjungsi tersebut dapat dilihat pada kutipan berikut.

32) Dan tengah bermimpi (III.10)

Penggunaan konjungsi dalam lirik lagu Ebiet G. Ade mempunyai peran bagi terwujudnya wacana lirik lagu yang baik. Konjungsi dan memiliki pemakaian tinggi dalam sebuah wacana. Hal tersbut dapat menandai banyaknya penggunaan konjungsi “dan" digunakan pada wacana lirik lagu untuk merangkat dua kalimat tunggal.

\section{b. Analisis Aspek Leksikal "Nyanyian} Rindu"

Dalam analisis aspek leksikal, sebagai penanda koherensi wacana lagu "Nyanyian Rindu" terdapat penanda, yaitu kolokasi (sanding kata).

a. Repetisi (pengulangan)

33) Apa yang seharusnya aku lakukan

Lakukan bila larut tiba

Pengulangan terdapat pada kata "lakukan" yang berada dalam satu bait. Kata lakukan di repetisi pada baris berikutnya. Kata lakukan menekankan bahwa lakukan apa pun yang baik diwaktu kapanpun.

b. Kolokasi (sanding kata) 34)Wajahmu yang bening sejuk (III.13)
Sanding kata yang terdapat dalam lirik lagu tersebut terdalpat pada frase "bening sejuk". Bentuk bening sejuk menunjukkan kolokasi yang memiliki asosiasi tertentu, yaitu keteduhan. Keteduhan pada wajah seorang perempuan.

\section{SIMPULAN}

Dari uraian tersebut dapat disimpulkan lirik lagu "Nyanyian Rindu" karya Ebiet G. Ade terdapat aspek gramatikal dan leksikal. Pada aspek gramatikal terdapat pengacuan, pelesapan, dan konjungsi. Selain itu ada aspek leksikal terdapat repetisi dan kolokasi. Terdapat 34 data yang menunjukkan aspek gramatikal dalam lirik lagu Nyanyian Rindu" karya"Ebiet

G. Ade". pengacuan terdiri atas 21 data, pelesapan 10 data, dan konjungsi 1 data. Aspek leksikal menunjukkan 2 data terdiri atas 1 data kolokasi dan 1 data repetisi.

\section{DAFTAR PUSTAKA}

Agustina, Rini. (2016).“Aspek Leksikal dan Gramatikal pada Lirik Lagu 'Jika' karya Melly Guslow". Bahastra, Oktober 2016, Volume XXXVI, Nomor 1

Dwinuryati, Yustina, Andayani dan Retno Winarni. (2018). Analisis Kohesi Gramatikal dan Leksikal pada Teks Eksposisi Siswa Kelas

10 Sekolah Menengah Atas. Scholaria: Jurnal Pendidikan dan Kebudayaan, Vol. 8 No. 1, Januari 2018: 61-69.

Hartono, Bambang. (2000). Kajian 
Wacana. Semarang: Fakultas Bahasa dan Seni Universitas Negeri Semarang.

Jorgensen, Marianne W. (2007). Analisis Wacana: Teori dan Metode. Yogyakarta: Pustaka Pelajar.

Kridalaksana, Harimurti. (2008). Kamus Linguistik. Jakarta: Gramedia.

Kusrianti, Anik et.al. (2004). Analisis Wacana. Surakarta: Pakarraya Pakarnya Pustaka

Moernanty, Djokoso. (2007). EBIET G. ADE: Kembali Mambaca Tanda Zaman Lewat Album Baru. www.kabarindonesia.com. 10 Juni 2008. Pukul 14.00.

Mulyana. (2005). Kajian Wacana: Teori, Metode, dan Aplikasi Prinsip Analisis Wacana. Yogyakarta: Tiara Wicana.

Moleong, Lexy J. (2014). Metodologi Penelitian Kualitatif. Bandung: PT Remaja Rosdakarya.

Setiawan, Budhi. (2012). Pragmatik: Sebuah Pengantar. Salatiga: Widya Sari Press Salatiga.

Sudaryanto. (2015). Metode dan Analisis Bahasa Pengantar Penelitian Wahana Kebudayaan Secara Linguistis. Yogjakarta: Sanata Dharma University Press.

Sumarlam. (2009). Analisis Wacana. Surakarta: Pustaka Cakra.
Nama saya Oktarina Puspita Wardani. Saya lahir di Jepara, 03 Oktober 1987. Pendidikan terakhir Magister Pendidikan Bahasa Indonesia lulus pada tahun 2012 Universitas Negeri Semarang. Saat ini saya bekerja sebagai dosen di Prodi pendidikan bahasa dan sastra indonesia di FKIP Unissula. 
Susando Jurnal Bahasa, Sastra Indonesia, dan Pengajarannya

Volume 2- Nomor 2, Oktober 2019, (HIm 286-293)

Available online at: http://sasando.upstegal.ac.id

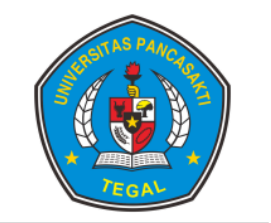

